This is an author produced version of a paper published in Work: A Journal of Prevention, Assessment and Rehabilitation. This paper has been peer-reviewed but does not include the final publisher proof-corrections or journal pagination.

Citation for the published paper:

Tengland, Per-Anders. (2013). A qualitative approach to assessing work ability. Work: A Journal of Prevention, Assessment and Rehabilitation, vol. 44 , issue 4 , p. null

URL: http://hdl.handle.net/2043/14854

Publisher: IOS

This document has been downloaded from MUEP (https://muep.mah.se) / DIVA (https://mau.diva-portal.org). 


\title{
A Qualitative Approach to Assessing Work Ability
}

\author{
Tengland, Per-Anders
}

\section{Introduction}

Work ability is a central concept in the laws governing sick-leave and early retirement pension [1]. It is also central in the evaluation of the need of, and the right to, treatment, rehabilitation, further education, competence enhancement, and skills development. Furthermore, the concept of work ability can be an instrument for vocational training, or for evaluating the employability of a job applicant, and even for deciding levels of wages [2, pp. 14-15]. For these reasons we need to be able to assess, or measure, the extent to which individuals have or lack work ability, and it is therefore important to construct well-designed instruments that measure it. Thus, this is of practical importance, for example in helping to decide who is entitled to sick-leave and who is not, or in finding out how to best help rehabilitate individuals who have wholly or partly lost their work ability.

Most general assessments of work ability are made using quantitative instruments. It is crucial for these kinds of instruments to be validated. There are several ways of going about this task. The most common approach to constructing and validating instruments leads, as I will show, to several kinds of problems, some of which are of a conceptual kind, and some of which are of a practical kind. In trying to solve these problems it will be suggested that in order to assess an individual's specific work ability we need to proceed in a more qualitative way.

But, first, we have to decide what we need an instrument for, since its use will partly dictate what it will contain. There are at least five possible aims for such an instrument: 1) sickness benefits: to help determine if the person is entitled to sick-leave (or the equivalent), 2) rehabilitation: to help people increase their work ability through finding various kinds of strategies for rehabilitation (in a broad sense), 3) evaluation: to specify the typical work requirements, or to evaluate work performance, in a profession, 4) education: to determine what knowledge, competence or skill is needed for a specific kind of work, and 5) research: to conduct research in the areas just mentioned. The different purposes will probably result in partly different instruments, but we might also find an overlap, where an instrument might be used for more than one purpose.

Reprinted from Work: A Journal of Prevention, Assessment and Rehabilitation, vol x, issue $x$, Tengland, Per-Anders, A qualitative approach to assessing work ability, p. xx, Copyright (2012), http://dx.doi.org/10.3233/WOR-2012-1361 with 


\section{Aim, Method and Procedure}

This is the second paper in a series of three, where the first paper discusses the concept of work ability [3], and the third one is intended be an empirical evaluation of the questionnaire or instrument that is the result of this present paper. This paper is purely theoretical and arguments will be presented concerning how to construct a questionnaire for evaluating work ability on the basis of a conceptual theory to be presented.

More specifically, the aim of this paper is to create and present a questionnaire (or an "instrument") that can be used for evaluating (specific) work ability in persons who are on medium- or long-term sick-leave or have lost their jobs due to the loss of (some of) their work ability, but where the person has some remaining degree of work ability, and/or is expected to increase her work ability through rehabilitation, and/or where it can be expected that changes in the work tasks or work environment could help the person perform her job. The practical purpose of the questionnaire will be to help map the various reasons why the person cannot work (fully) and relate this to different possible measures which might help her back to (her specific kind of) work. It should be usable in rehabilitation, in the broad sense of the term, i.e. for rehabilitation of work ability, but not necessarily of function or functional ability. To the extent that there are other concepts, e.g. "work capacity" or "work functioning", that are expected to serve the same purpose as the concept of work ability, they will be covered by the discussion in this paper. The instrument sought should try to take into consideration some requirements for what Innes and Straker call "work-related assessment" and/or "vocational assessment" [4]. Primarily, this means that the questionnaire should be specific and flexible, and that work ability should be contextualized.

As a foundation for constructing this questionnaire, the paper will use a conceptual theory of work ability. This approach takes its starting point in a previously performed explication of the concept of "work ability" [3]. The method in the present paper will be to logically deduce questions for the questionnaire from the conceptual theory of work ability previously constructed. Thus, the definition of work ability, presented shortly, will help provide us with the relevant questions, or, rather, question areas or topics.

In what follows I will first present some general comments on the problems of creating validity for quantitative instruments supposed to measure work ability. In this process some earlier instruments and approaches will be presented, and arguments will be given that illustrate what their general problems are. I will, then, try to show how we can increase validity through using the aforementioned conceptual theory (and through a definition of the concept of "work ability"), which can function as a model for creating instruments, quantitative or qualitative, that measure or evaluate work ability. Despite this possibility of improving the validity of quantitative instruments, I will argue that they will all partly fail, for

Reprinted from Work: A Journal of Prevention, Assessment and Rehabilitation, vol x, issue $x$, Tengland, Per-Anders, A qualitative approach to assessing work ability, p. xx, Copyright (2012), http://dx.doi.org/10.3233/WOR-2012-1361 with 
both logical and practical reasons. I will therefore, finally, go on to suggest an alternative, qualitative approach (or instrument) for evaluating work ability. This approach will, it is argued, create better possibilities for evaluating work ability, identifying problems with the work ability, and finding measures to alleviate problems found.

\section{Problems concerning Measurements}

There are a number of instruments that are used in trying to assess work ability, work capacity, work performance, functional capacity, work functioning, etc. $[5 ; 6 ; 7 ; 8 ; 9 ; 10 ; 11$; 12]. Most of them include questions about both physical and mental functions, with some emphasis on the physical ones, but a few focus primarily on mental functions [6; 10]. Usually these instruments are quantitative. They are normally used in a medico-legal context [2] and many of them have a dual function, namely to assess the work ability of the individual in relation to sickness benefits, and to evaluate the need for rehabilitation measures.

There are several problems with these instruments or questionnaires. One problem is that of validity, i.e. if the instrument measures what it purports to measure. This problem partly has to do with using poor definitions of the relevant concepts [4]. Another problem has to do with usability or feasibility. The existing instruments, whether valid or not, often use a roundabout way of mapping a person's work ability. These problems are not unique to this area. There are instruments in a number of areas, e.g. health, mental health, well-being, quality of life and empowerment, that are constructed in similar ways $[13 ; 14 ; 15 ; 16]$, and have similar problems.

\subsection{Validity}

There are various ways of trying to ascertain validity. Most instruments are created by way of some kind of conceptual approach, in that they consist of questions or items that have been chosen, for example, through focus group interviews or interviews with professionals in the field (and sometimes with lay people) [17, p. 16 ff.]. A questionnaire of this kind, then, consists of characteristics or items that professionals (and lay people) intuitively think of as belonging to the concept in question. ${ }^{1}$ These linguistic intuitions take us some way towards a valid instrument, since they have some degree of content or face validity, but they do not take us all the way. One reason is that our linguistic intuitions differ. This means that, even if researchers agree on some items, there will be a number of other disparate questions or items where researchers will not agree. Furthermore, there is a risk that the list will become rather

\footnotetext{
${ }^{1}$ Note that this procedure is sometimes called empirical [17, p. 8], suggesting that the phenomenon characterized could be identified through empirical means. This is not so. It is an empirical investigation into the conceptual use by professionals (and lay people).
}

Reprinted from Work: A Journal of Prevention, Assessment and Rehabilitation, vol x, issue $x$, Tengland, Per-Anders, A qualitative approach to assessing work ability, p. xx, Copyright (2012), http://dx.doi.org/10.3233/WOR-2012-1361 with permission from IOS Press. 
long, especially if we want to add all the various kinds of items that people suggest. ${ }^{2}$ Note that choosing (what to include) from this list will not be easy, since there are (in general) no criteria, other than our personal linguistic intuitions, to help us make such choices. ${ }^{3}$ If these intuitions differ, one possibility seems to be to vote [18], which is not a very satisfactory solution.

This very common approach does not take a full-fledged conceptual theory as its starting point. As I try to show elsewhere, using a conceptual theory as a starting point could improve the validity of quantitative instruments [19]. It will not, however, as I will later argue, solve all the problems that are inherent in these kinds of instruments. But it can be the foundation for another kind of evaluation of work ability. But before seeing how, let us investigate what such a conceptual theory amounts to.

\subsection{A Conceptual Theory of Holistic Work Ability}

In order to be able to create an instrument for evaluating work ability we need to use a conceptual theory of "work ability", and the definition that is part of this theory. "Work ability" is not, however, a "natural kind" concept. This means that we require a nominal definition, not a real (or descriptive) one. We have to decide what we want the term to mean, i.e. it involves a fair amount of stipulation in which several criteria are used to determine what characteristics belong to the concept, and what characteristics do not [3]. The method used for this process is conceptual analysis [3]. Finding such a definition involves a compromise between the criteria used, i.e. the process results in an explication of the concept $[20 ; 21]$. The explication should lead to a theoretically sound and practically useful conception [3].

Conceptual theories of this kind are suggested by several authors $[22 ; 23 ; 2 ; 3]$, and similar ideas are found in [24] and [25], although they do not contain full-fledged conceptual theories. These theories in particular see work ability as a holistic and dynamic concept, i.e. as a complex and changeable relation between the acting subject (including her health and competence), work-related goals or tasks, and the work environment. These ideas are in accordance with much that has been written in recent years in occupational science on rehabilitation, e.g. by Kielhofner [26] (see also [27] and [4]).

The explication referred to above resulted in two conceptions of work ability, a general one covering all the kinds of work that the individual's work ability might be related to, and a more specific one, only related to the specific kind of job that the individual has, or has

\footnotetext{
${ }^{2}$ There are, of course, strategies for reducing these questions [17].

${ }^{3}$ There are also strategies for eliminating items that co-vary [17]. Co-variation does not, however, show that the items are conceptually identical. Thus, eliminating a co-varying item risks losing some important information. There might, for example, be a strong causal relation between two items. Eliminating one robs us of the possibility to detect this relationship.
}

Reprinted from Work: A Journal of Prevention, Assessment and Rehabilitation, vol x, issue $x$, Tengland, Per-Anders, A qualitative approach to assessing work ability, p. xx, Copyright (2012), http://dx.doi.org/10.3233/WOR-2012-1361 with permission from IOS Press. 
previously had, and might be educated for [3]. Since we cannot use both here, we will focus on the latter, more specific, kind of work ability. A similar questionnaire can be made for the other, general, kind of work ability. Let me present the definition of work ability that is the result of the previously mentioned philosophical explication of the concept, one that gives us a requirement for having (at least) acceptable (specific) work ability:

A person has specific work ability if (and only if) the person has at least one relevant subset of the manual, intellectual and social (i.e. occupational) competence, together with the physical, mental and social health that is required for the competence, and has (some set of) basic occupational virtues and the relevant job-specific virtues (if there are any) that are necessary in order to reach the work-related goals (and/or perform the work-related tasks), with at least normal quality standards, that can typically be reached (or performed) by someone in the profession, given that the physical, psycho-social and organizational environment is acceptable (or can easily be made acceptable), and if the person is (at least) minimally motivated for the job, i.e. can stand it (adapted from [3]).

A few explanatory remarks are required (see [3] for more details). 1) Occupational competence is, as expected, the key requirement for having work ability (at least for skilled work). However, it need sometimes only involve a relevant subset of the possible know-how and skills that are covered by an occupation. Everyone does not do everything within their profession. For example, some academics only teach, while others do research. 2) Health is also required, but only to the extent that the (subset of the) competence requires it. Thus, having work ability is compatible with having reduced health. Some degree of health is, of course, always needed, e.g. being able to think and communicate. 3) Having work ability also requires a certain number of work-related characteristics or virtues, such as diligence, loyalty, kindness, helpfulness, reliability, and conscientiousness. Not every possible occupational virtue is needed, but a set sufficient for functioning in the work place is necessary. A lack of one or a few such virtues might be compensated for by several others. 4) For some jobs it is also necessary to have some specific character trait or virtue, such as being extra courageous (e.g. firefighters), extra conscientious (e.g. computer programmers), or extra patient (e.g. teachers). 5) The person also has to have some basic health-related motivation (energy or vitality), e.g. she has to want to get out of bed in the morning. It is not necessary for her to like the job in question, but in order to have work ability she must be (at least) minimally motivated for it, i.e. be able to stand it. Finally, the competence also 6) has to be related to the work tasks and 7) has to be related to the work environment. The work tasks (that we relate work ability to) should be such that the (competent, healthy, and virtuous) individual can be expected to be able to perform them, and the environment should be acceptable, i.e. it should

Reprinted from Work: A Journal of Prevention, Assessment and Rehabilitation, vol x, issue $x$, Tengland, Per-Anders, A qualitative approach to assessing work ability, p. xx, Copyright (2012), http://dx.doi.org/10.3233/WOR-2012-1361 with permission from IOS Press. 
be such that a worker typically can get her work done in it. Note that an "acceptable work environment" might sometimes be quite demanding, as can be the case for miners, emergency ward personnel, and school teachers.

The reason for the last two definitional requirements is that we want to be able to differentiate between problems to do with work ability and problems in the work environment (broadly conceived). For example, when a crucial machine breaks down we locate the problem in the work environment, i.e. the machine, not in the work ability of the person working with the machine, and if the work requirements are exceptionally high we do not blame a failure to complete the tasks on the lack of work ability, but rather on the all too high requirements. Figure 1 displays the relations between these characteristics.

\section{Figure 1: A model for having work ability}

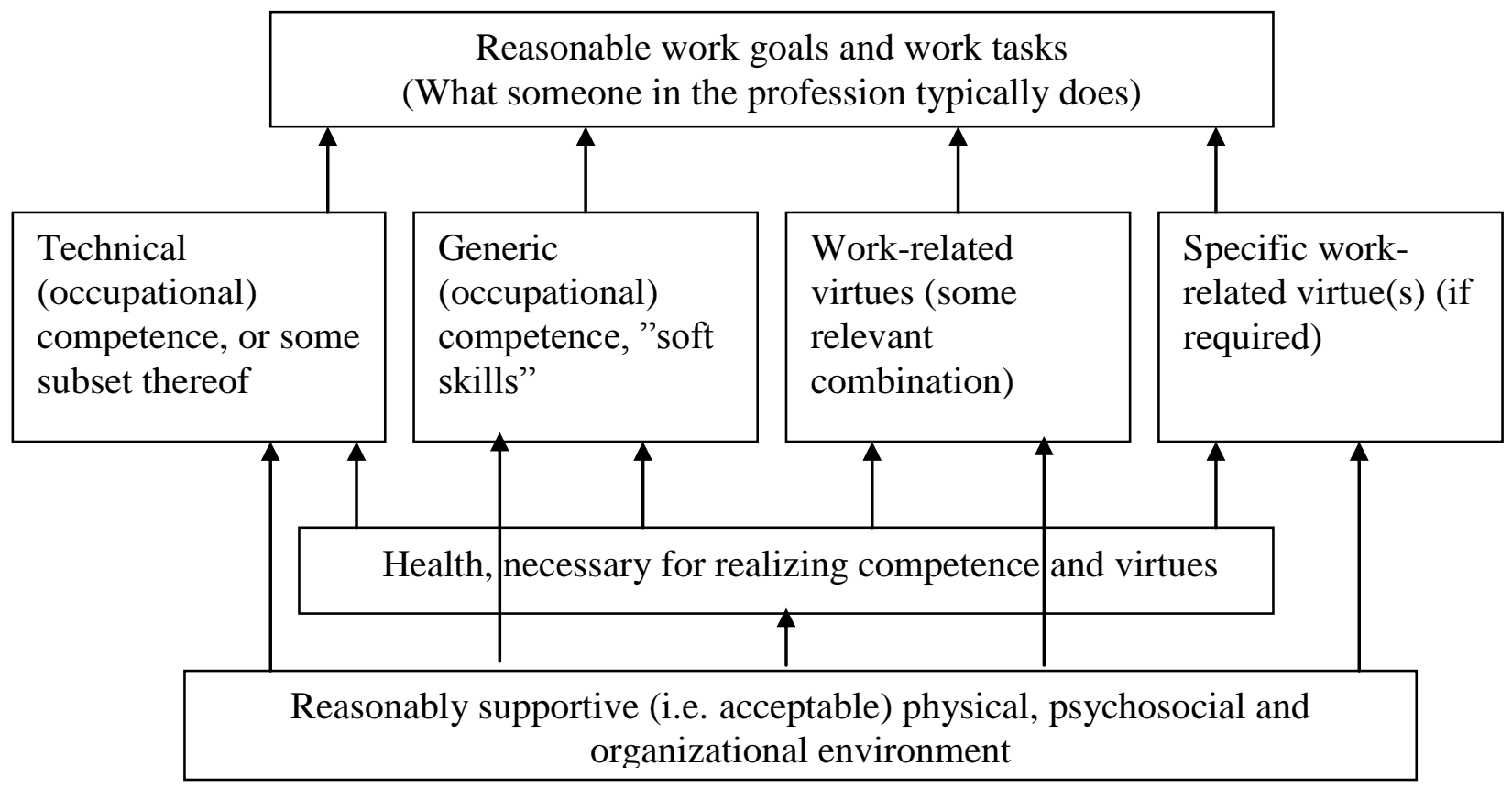

Figure 1: The environment and the health of the individual are external and internal foundations for the technical and generic work-related competence and the work-related general and specific virtues that are (together) needed in order to reach (reasonable) work goals and perform (reasonable) work tasks. The arrows indicate support or requirement for, or causal influence on, the upper levels.

Thus, this theory takes its starting point in the general, holistic ability of the individual, specifies the major features of the individual that are required for having work ability (health, competence, motivation and occupational virtues), and relates them to the work tasks and the work environment. The environment functions as a platform for action, which can support the

Reprinted from Work: A Journal of Prevention, Assessment and Rehabilitation, vol x, issue $\mathrm{x}$, Tengland, Per-Anders, A qualitative approach to assessing work ability, p. xx, Copyright (2012), http://dx.doi.org/10.3233/WOR-2012-1361 with 
individual in achieving her work-related goals, or (in less beneficial circumstances) make it harder or impossible for her to reach them.

The dynamics of the conception have to do with several things: there might be several ways in which the (relevant) goals can be reached and the tasks performed, there might be several kinds of goals and tasks (relevant for the job), and the work environment might change in ways that make the job easier or harder. A change in one area will affect other areas, and there will be several ways of accommodating to the change. The theory also takes the complexity of the individual's internal features into account - her mental, social and physical health, her basic and her occupational competence, and her occupational virtues and character traits - without reducing all of these features to physical or mental functions, as a medically or functionally oriented theory would (see [28]). It also takes into account the fact that the same kind of job can look very different for different individuals. There is a variation in many kinds of work that makes them, more or less, impossible to specify beforehand, in any detail. As we saw, a person often only deals with a subset of the possible tasks within a profession. We can also find a lot of variation (within the same kind of work) when it comes to work environments. They can change or vary continually, e.g. truck drivers might meet all kinds of different traffic situations depending on where and when they work.

An instrument, quantitative or qualitative, created from the conceptual theory presented here would have to take all this into account. The theory would function as a criterion for choosing items, questions or topics for the instrument. We would know which general kinds of items follow logically from the theory and definition, and, thus, what kinds of specific items the instrument should contain. It should, of course, also be reasonably exhaustive, i.e. we have to secure content validity [17]. But, as will be illustrated below, an approach of this kind would not solve all problems for all kinds of instruments. Due to the complexity of work ability, a quantitative questionnaire is hard, or even impossible, to create.

\subsection{Problems with the Dynamic Aspect of Work Ability}

As the definition of "work ability" shows, health-related abilities, skills and competences are not used and cannot be assessed in a vacuum. In order to assess to what extent the person has work ability, we have to know what her work tasks are and what her work environment is like. The consequence is, then, that it is impossible to formulate questions that can be used for all kinds of work (see also Hart et al. 1993, in [4]), except for very general items, such as "The work environment is supportive of my work." Creating a general questionnaire therefore seems theoretically impossible, unless we add open, or qualitative, questions that take the environment and specific tasks into account [2].

One option might be to create an instrument for each kind of work, where health and competence are related to specific work tasks and work environments. But even this would

Reprinted from Work: A Journal of Prevention, Assessment and Rehabilitation, vol x, issue $x$, Tengland, Per-Anders, A qualitative approach to assessing work ability, p. xx, Copyright (2012), http://dx.doi.org/10.3233/WOR-2012-1361 with 
not suffice, since there is a lot of variation within many kinds of jobs, e.g. a police officer might do very different things depending on where, and with what, she works. There is a big difference between doing administrative work, patrolling, interrogating witnesses, and working undercover. Without knowledge about the individual's specific tasks and environment one is left with very general questions about the person's functions, abilities, skills, character traits, etc. But since we know that the reduction of a specific (bodily or mental) function or ability will affect different kinds of jobs differently, and even the same kind of job in different contexts, we cannot really say if, or how much, the disability reduces the work ability of the person. We should not forget the enormous flexibility and adaptive ability of humans, including our ability to change the environment. A specific task can often be fulfilled in many different ways (see [2]). Signing a contract can, for example, be done by writing on a sheet of paper, shaking hands, entering a code on a computer, or recording vocally what is agreed upon.

These complexities might be one reason why so few instruments take the tasks and the environment into consideration, and instead focus primarily on functions and abilities (e.g. [5] and [8]).

\subsection{Superfluous Questions}

Another problematic aspect is that most questionnaires that are generic will contain a lot of unnecessary questions, or "noise" [17, p. 23], since we do not (when constructing the instrument) know anything about the specific problems of the individuals that fill in the questionnaire [27]. Thus, we have to take all possibilities into account. For example, the Norwegian Scheme of Functions [8], based on the ICF [29], consists of 40 questions (out of the 120 possible ones in the ICF), divided into eight categories (walk/stand, hold/pick, lift/carry, sit, master, cooperation and communication, perception, and general work ability), and a similar Dutch instrument [9], also based on the ICF, covers 56 functional descriptions divided into six categories (personal functioning, social functioning, adaptation to physical environment, dynamic actions, static postures, and working hours). Similarly, a Swedish instrument, the AWP (Assessment of Work Performance) index, consists of close to 50 questions about work functioning, divided into three main categories: motor skills, process skills and communication and interaction skills, each divided into four or five sub-categories, e.g. posture, mental energy, physical communication, and interaction [7]. In England, similar instruments, or approaches, are used, e.g. PCA (The Personal Capacity Assessment), which contains 14 (multi-choice) questions about physical activities, and 25 (yes/no questions) about mental disabilities, divided into four main areas: completion of tasks, daily living, coping with pressure, and interaction with other people [11]. Although all these instruments differ in several respects, they all try to cover what they want to measure by using a relatively large

Reprinted from Work: A Journal of Prevention, Assessment and Rehabilitation, vol x, issue $x$, Tengland, Per-Anders, A qualitative approach to assessing work ability, p. xx, Copyright (2012), http://dx.doi.org/10.3233/WOR-2012-1361 with 
number of questions. However, it is usually neither necessary nor fruitful to ask all these questions [17, p. 23]. It is, furthermore, rather telling that these instruments purporting to measure more or less the same thing (and being used for similar purposes) have so vastly different sets of questions.

Let us consider in what ways a person's work ability can be reduced: 1) A person's work ability can be reduced to some extent in all its various aspects, as when the person has moderate chronic pain. 2) One specific work-related ability (or some work-related abilities) can be totally absent (where some or most are present), as when the person has broken a leg and cannot walk or stand, but can use her upper body and her intellectual and emotional abilities. 3) One specific work-related ability (or a few work-related abilities) can be partly absent, (where some or most are present), as when a person has sprained her wrist and cannot use the computer as efficiently as before. In none of these three kinds of cases does it seem relevant to know or ask about all the possible health- and work-related functions, abilities, or competences of the individual. Rather, it seems more reasonable to go straight to questions about what specific tasks can and cannot be performed (in the present environment), and to what extent there is a reduction in the performance of these tasks (if there is such a reduction).

\subsection{Other Complexities}

There might also be causes other than illness or disease that reduce the ability to work and that we want to find out about. The (work) environment might have changed, as when farmers have to change crops (or livestock) due to a changing climate; tasks might have become more demanding, as when a nurse now has to be able to handle more advanced equipment; or the professional competence or skills might be old and outdated, as when computers replaced typewriters. The kind of work done might not be required any more, or it might be replaced by machines or other professions. In these cases asking about basic health- or work-related functions or abilities is not very useful.

Furthermore, we might not primarily be interested in functions, especially not in basic functions, such as being able to frequently reach out, to change postures, or to stand noise [9]. Rather, we might be more interested in "higher-level" goal or task accomplishments, such as vaccinating a patient, negotiating a business deal, or driving a truck. This level will also require more generic abilities ("soft skills"), such as being able to show empathy, co-operate, plan ahead, learn, and solve problems, i.e. complex abilities that are not so frequently asked about. They are, for example not asked for in the AWP [7] or in the Norwegian Scheme for the Assessment of Function [8]. We might also be interested in a person's character traits, since those can be very relevant to some kinds of work, as not every person has a character (or the necessary virtues) suitable for every kind of job, e.g. the compassion needed to be a psychotherapist. Few, if any, instruments take this into account.

Reprinted from Work: A Journal of Prevention, Assessment and Rehabilitation, vol x, issue $x$, Tengland, Per-Anders, A qualitative approach to assessing work ability, p. xx, Copyright (2012), http://dx.doi.org/10.3233/WOR-2012-1361 with permission from IOS Press. 
Note, finally, another possible problem, which might not constitute a reduction of the work ability as such, but which might contribute to problems in performing the work. Some people find themselves in a private situation that hinders work. There might be sick children that stop the person from going to work, or a chronically ill parent that needs attentions, or the marital situation might be such that the individual is kept away from work now and then. What appears to be a problem with the individual's work ability might be the inability to cope with work and private life at the same time. In a situation like this the person's work ability might still be intact, and the tasks and the work environment can be reasonable. Even if this problem has its origin outside the occupation, and might be hard to do something about, it might be important to understand what all the causes that contribute to the problem are. When investigating the work ability of an individual, one should, then, take these considerations into account, and, if possible, questions that cover this more private area should be included.

To conclude this first section: Due to the failure of many instruments to capture the dynamic complexity of work ability and to the roundabout process of trying to measure work ability in terms of functions or abilities, we seem to need another approach in evaluating the work ability of the individual. Thus, we need an approach closer to that which Streiner and Norman call "patient-specific" [17, p. 23] - one that is also situation-specific.

\section{Evaluating Work Ability}

Thus, it seems that in the process of evaluating the degree of a person's work ability a lot of time might be wasted on asking unnecessary questions. It would make the instrument more efficient, if we could go straight to the problem. We also want to capture the complexity and the dynamic aspects of work ability and still have an instrument that can be used for all kinds of work. Furthermore, if we are interested in restoring a person's work ability, it would be preferable if we could also make the person concerned more involved in this process. If used wisely, the evaluation process could help give her more control over her work situation, i.e. increase her empowerment [30]. This is an ethically preferable situation, for both intrinsic and instrumental reasons. Participation, in general, both strengthens autonomy and self-esteem (intrinsic reasons) and makes progress or success more likely (an instrumental reason) [10].

As already indicated, the most effective way of finding out whether or not a person has (specific) work ability is to start by investigating what specific work-related goals or tasks she has, to what extent she can reach or perform them, and to what extent her work environment is facilitative of her work [31]. The questions should be posed by someone familiar with work tasks and work environments, for example by an occupational therapist (or the equivalent), and should be answered by the employee, some questions preferably together with the employer (or supervisor) at the work place, if there is one [31]. Some of the final questions

Reprinted from Work: A Journal of Prevention, Assessment and Rehabilitation, vol x, issue $x$, Tengland, Per-Anders, A qualitative approach to assessing work ability, p. xx, Copyright (2012), http://dx.doi.org/10.3233/WOR-2012-1361 with 
might not be answerable by the individual herself, but might require consulting a health professional, e.g. a physiotherapist or a doctor.

In the following section I will explain how we might go about creating this alternative way of evaluating work ability, following a more qualitative procedure. The definition of work ability presented earlier will function as a guide to what questions to ask, or what topics to cover.

\subsection{A Qualitative Approach}

Before starting the interview we have to make clear that the kind of work the individual is trained for is still available, either with the present employer or, if unimployed, on the present job market. If it is not, we need to investigate what other job options there are for the person, and relate the questions to (one of) these options. If it is clear that the person cannot work with her previous work (or if it is not available) but might be able to continue working with some kind of (unspecified) work, we need to change to a more general questionnaire (not discussed or provided in this paper).

We will in the following assume two things: first, that the person has, or has had, a specific job, or has a specific education or training, in relation to which the evaluation is being made, and, second, that there is some difficulty in achieving her present work goals or performing her present work tasks. Therefore, the most natural starting point seems to be to investigate what kind of work the individual is presently supposed to manage.

First, we need to map the goals (and sub-goals) that the individual has to achieve and the tasks (and sub-tasks) she has to perform as part of her work. Second, we have to determine what the problems in work performance are (i.e. problems in reaching goals or performing tasks), and to what degree there is such a problem (i.e. investigate the discrepancy between what is required and what can be achieved). Third, in order to see if the problem has to do with work ability or not, we have to evaluate if the goals or tasks are reasonable, and if the methods or strategies used are appropriate and effective. Fourth, we have to see if the environment, including tools and machines, is acceptable, or if it is the cause of the problem. If the goals and tasks are unreasonable or the methods inappropriate, or if the environment is unacceptable, then we need go no further. Then the problem is not one of work ability, and the solution is to make goals, tasks, and methods reasonable and the environment acceptable. However, if there are no (or only minor) problems in these respects, then the problem has to do with work ability, or perhaps some other (outer) hindering circumstance.

Then follows a section of questions where we locate the source of the problem. Does the problem have to do with the motivation or health, with the technical or generic competence, or with the character or personality of the individual? When we map these areas, and come to understand what the problems are, and from where they emanate, we are in a position to ask

Reprinted from Work: A Journal of Prevention, Assessment and Rehabilitation, vol x, issue $x$, Tengland, Per-Anders, A qualitative approach to assessing work ability, p. xx, Copyright (2012), http://dx.doi.org/10.3233/WOR-2012-1361 with 
follow-up questions about what can be done about them, i.e. what kind of help might be needed.

A reduction in work ability does not necessarily stop the individual from being able to work, if other changes can be made. Thus, a further set of questions will investigate if, how, and to what extent, we can change the work tasks and work goals, the methods or strategies used (to make them better fit the present competence and health status of the individual), or the physical, psychosocial or organizational environment, in order to compensate for the relative lack of work ability.

Finally, we end with a few questions trying to identify outer factors that make work harder, including the person's private life. ${ }^{4}$

We do not, at this point, need to know whether or not the person uses specific mental, social or physical functions or abilities in her job, and if there are problems with these functions. This will, however, be necessary if there is a need for medical or psychological rehabilitation, or treatment.

\section{Questionnaire}

In this final section, I will show how an evaluation "instrument" that takes all of the points made above into account might look. Explanations of the various sections and questions will follow as we go along. The general approach is to use a relatively structured interview which is expected to result in open and detailed answers.

Note the following points concerning the questions and the interview situation:

1) The order of the questions is not important, as long as all the relevant questions are covered. If the answer to one question leads to another that is not the next one in the instrument, that is acceptable. It is preferable for the meeting to result in a conversation about the person's work ability and work situation rather than a strict interview.

2) The questions are formulated in a standardized way, but only for simplicity's sake. This is not a standardized instrument. The questions can be asked in other ways - ways that might suit the interviewer or the interviewee better, as long as the general topics of the questions are covered.

3) A question might lead to further probing questions. That is, the interviewer will have to decide when the question is sufficiently well answered. Nothing prevents the interviewer from returning to an earlier question.

4) All the questions will not be relevant for every interviewee. Questions that are obviously unnecessary should be skipped. Certain conditions of ill health, such as a broken leg, will probably require fewer questions, and will be easier to find remedies and compensatory

\footnotetext{
${ }^{4}$ There is nothing that prevents us from changing the order of some of the sections of questions. Especially section two and three might be reversed. In some cases a whole section, such as section two, might be skipped. What is the problem (and the remedy) might be all too obvious.
}

Reprinted from Work: A Journal of Prevention, Assessment and Rehabilitation, vol x, issue $x$, Tengland, Per-Anders, A qualitative approach to assessing work ability, p. xx, Copyright (2012), http://dx.doi.org/10.3233/WOR-2012-1361 with 
measures for, than more diffuse health problems, such as stress-related problems and mental illness.

5) The interview situation should be empowering, in the sense that the person's autonomy should be respected, her resources used and her thoughts and ideas taken seriously. The interview should, if possible, be voluntary.

6) Some questions, e.g. about work tasks and the work environment, should preferably be answered together with an employer, and others, e.g. about possible treatment, with some kind of health-care worker.

\subsection{Identifying the Problem}

We start by asking the person what her present occupation is, and what her present workrelated goals and tasks are, but also what education she has, since these might not correspond. We also need to know, especially when it comes to long-term unemployment, if the job is still available.

Question 1a: What is your present (or latest) occupation?

Follow-up question 1b: Is that job, or that kind of job, still available?

Follow-up question 1c: Do you have any other education, training or (extensive) work experience?

The point of the last question is that training or rehabilitation, if needed, could be directed towards this other kind of work if it turns out to be impossible or hard to rehabilitate in relation to the present kind of job, or if it is no longer available.

Question 2a: What are your present (or, in the case of unemployment, expected) work goals, or tasks?

Follow-up question 2b: What do you, specifically, have to do in order to reach these goals, or perform these tasks?

These answers will provide us with a list of goals and tasks, from more general goals and tasks to more specific ones. Now that we know what the goals and tasks are, we need to know to what extent they can or cannot be reached, under the present circumstances.

Reprinted from Work: A Journal of Prevention, Assessment and Rehabilitation, vol x, issue $\mathrm{x}$, Tengland, Per-Anders, A qualitative approach to assessing work ability, p. xx, Copyright (2012), http://dx.doi.org/10.3233/WOR-2012-1361 with 
Question 3: Which of these goals cannot be reached and which tasks cannot be performed (in the present circumstances)?

This identification can range from the most general goals (e.g. negotiate a deal) to the most low-level tasks (e.g. press a key). Since the problem might only be one of degree, we also need to know to what degree these tasks can or cannot be performed. It might, however, be the case that questions 3 and 4 can be answered together.

Question 4: Could you specify, as far as possible, your degree of disability for each task or goal identified?

In order to differentiate between problems that lie "within" the individual, such as ill health, lack of motivation, lack of competence, and character, and those that belong to her outer milieu, we now have to see if the tasks or goals are reasonable, i.e. such that they can be expected to be managed or achieved.

Question 5a: Do you consider the tasks and goals that you are supposed to manage and reach reasonable for someone in your position/profession?

Clarifying question (if necessary) 5b: Would you expect someone else with your kind of professional background to be able to handle a similar situation regarding tasks and goals?

We also need to know if the physical or psychosocial environment is an obstacle, and if so, to what extent. This is, however, not (yet) an investigation into ways in which the environment could be improved to compensate for lost or reduced functional capacity or ability. It is about identifying abnormal environmental conditions, those which would make work harder or impossible for anyone. ${ }^{5}$

Question 6: Are there any (physical, psychosocial, and organizational) environmental problems that hinder your normal work or your normal performance, and that can be relatively easily changed?

We now know if the problem is one of reduced work ability, or one where goals/tasks are unreasonable or the environment is unacceptable. If it is the two latter, these problems should

\footnotetext{
${ }^{5}$ If a problem of this kind is obvious, it might be possible to go straight to it in the beginning of the interview. However, since not every environment problem is obvious, it might still be important to include the question at this point.
}

Reprinted from Work: A Journal of Prevention, Assessment and Rehabilitation, vol x, issue $x$, Tengland, Per-Anders, A qualitative approach to assessing work ability, p. xx, Copyright (2012), http://dx.doi.org/10.3233/WOR-2012-1361 with permission from IOS Press. 
be addressed/solved by the employer, and the interview ends here. If the problem is not one about overly demanding goals/tasks or an unacceptable environment, we can conclude that it has to do with reduced work ability, or some other, external problem. We now have to locate the problem (in more detail) and find solutions to it.

\subsection{Possible Remedies Relating to the Individual}

This part of the questionnaire will investigate what the problem is, and what kind of help the individual might need in order to alleviate the problem. Four general questions areas will be addressed: motivation, health, competence, and character.

First we should investigate if the problem is motivational.

7a: Are you motivated for your work?

More specifically:

7b: Do you like or enjoy it?

7c: Can you tolerate, or at least, stand it?

If not, do you need to see a careers adviser to find a job that you are more motivated for?

Not liking the job is not the same thing as having reduced work ability. Still, the problem might have to be addressed. However, not having some minimal degree of motivation, or not being able to stand the job (or tasks), is having reduced work ability.

We also need to find out to what extent it is a health problem, or some other kind of problem, and what kind of professional help might be needed in order to increase or recover work ability.

8a: Is the problem caused by ill health of some kind?

If this is the case we need to know:

8b: Have you seen or do you need to see a doctor?

Can treatment help restore work ability?

8c: Have you seen or do you need to see a physiotherapist?

Can treatment or training help restore work ability?

8d: Have you seen or do you need to see a psychotherapist or counselor?

Reprinted from Work: A Journal of Prevention, Assessment and Rehabilitation, vol x, issue $x$, Tengland, Per-Anders, A qualitative approach to assessing work ability, p. xx, Copyright (2012), http://dx.doi.org/10.3233/WOR-2012-1361 with 
Can treatment or counseling help restore work ability?

Furthermore, we need to find out if the problem is due to a lack of relevant skills or competence (perhaps because of changing work demands).

9a: Is the problem caused by lack of relevant technical or generic (occupational) skills or competence?

If this is the problem, we need to know:

9b: Do you need further "manual" or "technical" training for your present occupation?

Is such training available?

Manual, or technical, training refers to learning to use specific instruments, tools, techniques or methods, such as using a chain saw, driving a bus, handling a new health-care device, or using a new kind of computer program.

9c: Do you need to develop your generic (general) occupational competences ("soft skills") for your present occupation?

Is such training available?

Generic competence (or soft skills) refers to broad competences, such as communication skills, problem-solving capacity, planning capacity, empathic listening, reasoning capacity, strategic capacity, creativity, flexibility, and co-operation skills.

9d: Do you need a new education or new occupational training?

Is such an education (or such training) available?

Do you need to see a study or careers adviser?

Finally, we need to investigate if the problem is a matter of personality (or character) or "suitability".

10a: Do you think that the job is suitable for you, considering your personality and character traits?

10b: Are there other jobs more suitable to your personality (or character traits)?

Do you need to see a study or careers adviser in order to find a more suitable job?

Reprinted from Work: A Journal of Prevention, Assessment and Rehabilitation, vol x, issue $x$, Tengland, Per-Anders, A qualitative approach to assessing work ability, p. xx, Copyright (2012), http://dx.doi.org/10.3233/WOR-2012-1361 with 
10c: Can you work with, develop, or change your character or personality?

Can counseling or treatment help increase or restore work ability?

Do you need to see/have you seen a psychotherapist or counselor?

The last issue might be the hardest to both ask about and do something about, since a person's character or personality might be hard to change. If there is a problem of this kind, finding a more suitable job is a more likely option.

\subsection{Compensating for the Problem}

Let us now turn to questions about the possibility to compensate for the reduced work ability, assuming that some of the person's work ability is intact. Is there anything in the work tasks or the work environment that can be changed in order for the person to be able to continue working, despite reduced work ability? (These questions about tasks and goals might be hard to differentiate from other organizational questions.) Questions 11 and 12 are best answered together with the employer (if there is one), preferably together with an occupational therapist.

\subsubsection{Questions Relating to Possible Changes in Work Goals and Work Tasks}

The following seven questions (11a-f) try to exhaust the different possibilities to change work goals and tasks.

Question 11a: Can the present goals be reached, or the present tasks be performed, through the use of other abilities, competences, techniques or skills that you possess (given the present environment)?

If so, how?

Question 11b: Can the present goals be reached, or the present tasks be performed, through the use of other means or methods that you have access to (given the present environment)?

Question 11c: Could you perform another set of tasks that would lead to your present work goals, wholly or partly?

If so, which?

Question 11d: Can you work more slowly with the same or with different tasks?

If so, with which of them?

Reprinted from Work: A Journal of Prevention, Assessment and Rehabilitation, vol x, issue $x$, Tengland, Per-Anders, A qualitative approach to assessing work ability, p. xx, Copyright (2012), http://dx.doi.org/10.3233/WOR-2012-1361 with 
Question 11e: Can you work part time with the same or with different tasks?

If so, how much, and with what?

Question 11f: Can you work flexible hours/days with the same or with different tasks?

If so, how much, and with what?

Question 11g: Is there another job (are there other tasks and goals) within your company/work place that you can manage or handle (wholly or partly)?

If so, which?

\subsubsection{Questions Relating to Possible Major Changes in the Environment}

We also need to know if the work environment can be changed in order to compensate for the relative lack of work ability.

Question 12a: Can the physical environment (including tools and machines) be changed in order to compensate for the reduction of work ability and make the fulfillment of work tasks easier?

If so, how?

Question 12b: Can the psychosocial environment be changed in order to compensate for the reduction of work ability, and make the fulfillment of work tasks easier?

If so, how?

Question 12c: Can the organizational environment (other than tasks, time and tempo) be changed in order to compensate for the reduction of work ability and make the performance of work tasks easier?

If so, how?

Question 12d: Is it possible to work at home, or outside of the normal work place (partly or wholly)?

If so, with what tasks and with what kind of environmental support?

\subsection{Employability and Home Situation}

Work ability is not the only important factor in getting and managing a job. There might be problems that are not strictly part of the person's work ability, but that nevertheless influence the ability to get work, or to work properly. Quite often the home situation influences the

Reprinted from Work: A Journal of Prevention, Assessment and Rehabilitation, vol x, issue $x$, Tengland, Per-Anders, A qualitative approach to assessing work ability, p. xx, Copyright (2012), http://dx.doi.org/10.3233/WOR-2012-1361 with 
work ability. Even if this situation lies within the private sphere, we might consider asking about it. In such a case, we have to know if, and, if so, to what extent, the home situation might be a hindrance to work performance.

Question 13a: Are there factors in your home situation that hinder work from being done (effectively) and that can be changed in order to improve work ability?

If so, which?

Follow-up questions: $13 \mathrm{~b}$ : Is there a need for counseling or family therapy?

13c: Is there a need for external changes (e.g. housing, child care)?

There might also be other ways, apart from increasing or restoring work ability, in which a person can increase her employability.

Question 14: Are there other factors that can be influenced which could make it easier for you to get or keep a job (e.g. transportation, driver's license, language skills)?

If so, which?

\section{Conclusion}

The paper started with a discussion of the shortcomings of some common and well-known (in general, quantitative) instruments that purport to measure work ability, or its equivalent. Those shortcomings primarily had to do with validity and with the roundabout way of assessing work ability. By presenting a definition of work ability, a method was envisaged for creating alternative approaches to constructing questionnaires. It was argued that a qualitative approach is the most plausible way of solving the problem. This resulted in an outline of a questionnaire that can be used for assessing a person's work ability, and that can help identify possible solutions to the various problems found.

Note, however, that there are purposes for which such a questionnaire should not be used. It is not an instrument suitable for intersubjective comparisons (i.e. comparing the work ability of different persons), although it might be used for intrasubjective comparisons (i.e. for assessing the work ability of the same person over time), assuming that the person has the same job when the questionnaire is used more than once. It does not give us statistical information and it therefore makes certain kinds of research impossible. But this is, obviously, not the purpose of the approach suggested.

Finally, the arguments for assessing work ability in the proposed way are mainly theoretical. Empirical tests (soon to be undertaken) will give us answers as to exactly how useful this qualitative questionnaire is, and for whom.

Reprinted from Work: A Journal of Prevention, Assessment and Rehabilitation, vol x, issue $x$, Tengland, Per-Anders, A qualitative approach to assessing work ability, p. xx, Copyright (2012), http://dx.doi.org/10.3233/WOR-2012-1361 with 


\section{Acknowledgements}

I would like to thank Lennart Nordenfelt, Kerstin Ekberg and the research group at RAR at Linköping University, Katarina Graah-Hagelbäck, and the anonymous reviewers for valuable comments on earlier versions of this paper. This work has been financed by the Swedish Council for Working Life and Social Research.

\section{Declaration of interests}

The author reports no declarations of interest.

\section{References:}

[1] Swedish Government Bill, 1962:381. Lagen om allmän försäkring [The National Insurance Act]. Stockholm: Ministry of Social Affairs; 1962.

[2] Nordenfelt L. The concept of work ability. Brussels: P.I.E. Peter Lang; 2008.

[3] Tengland, P-A. The concept of work ability. Journal of Occupational Rehabilitation, 2011; 21(2):275-285.

[4] Innes E, Straker L. A clinician's guide to work-related assessments, 2 - Design problems. Work, 1998; 11:191-206.

[5] Toumi K, Ilmarinen J, Jahkola A, Katajarinne L \& Tulkki A. Work Ability Index. 2nd rev. ed. Helsinki: Finnish Institute of Occupational Health. Occupational Health Care 19; 1998.

[6] Linddahl I, Norrby E, Bellner A. Construct validity of the instrument DOA: A dialogue about ability related to work. Work, 2003; 20(3):215-224.

[7] Sandqvist JL, Törnqvist KB, Henriksson CM. Assessment of work performance (AWP) development of an instrument. Work, 2006; 26(4):379-387.

[8] Brage S, Fleten N, Knudsöd, OG, Reiso H, Ruen A. Norsk funktionjonsskjema - et nytt instrument ved sykmelding og uførhetsvurdering. [Norwegian scheme of functions]. Tidskrift for Norsk Laegeforening. 2004; 124:2472-2474.

[9] De Boer WEL, Houwaart ES. Geschiktheid gewogen [Ability assessed]. Amsterdam: The Dutch Association for Insurance Medicine (NVVG); 2006.

[10] Norrby E, Linddahl I. Reliability of the instrument DOA: Dialogue about ability related to work. Work, 2006; 26(2):131-139.

[11] PCA (The Personal Capability Assessment Questionnaire). [Cited 2010 Oct 13] Available from http://www.tameside.gov.uk/benefits/capabilityassessment

[12] Boer WEL de. Quality of evaluation of work disability. Ph D Thesis. TNO: Hoofddorp; 2010.

[13] Nordenfelt L. Quality of life, health and happiness. Aldershot: Ashgate publishing; 1993.

Reprinted from Work: A Journal of Prevention, Assessment and Rehabilitation, vol x, issue $x$, Tengland, Per-Anders, A qualitative approach to assessing work ability, p. xx, Copyright (2012), http://dx.doi.org/10.3233/WOR-2012-1361 with 
[14] McDowell I, Newell C. Measuring health: A guide to rating scales and questionnaires. 2nd ed. Oxford: Oxford U P; 1996.

[15] Brülde B, Malmberg H. Measuring quality of life: Some philosophical comments.

Filosofiska meddelanden. Gröna serien, no 59. Göteborg: Göteborgs universitet, Filosofiska institutionen; 1998.

[16] Bowling A. Measuring health: A review of quality of life measurement scales. 3rd ed. London: Open University Press; 2004.

[17] Streiner DL, Norman GR. Health measurement scales: a practical guide to their development and use. Oxford: Oxford UP; 2002

[18] Lawshe CH. A quantitative approach to content validity. Personnel Psychology, 1975; 28:563-575.

[19] Tengland P-A. A conceptual approach to measuring psychiatric and psychotherapeutic treatment. In: Nordenfelt L, Liss P-E, editors. Dimensions of health and health promotion. Amsterdam: Rodopi press; 2003, p. 69-60.

[20] Carnap R. The logical foundation of probability. Chicago: University of Chicago Press; 1971.

[21] Ayer AJ. The central questions of philosophy. London: Penguin Books; 1991.

[22] Tengland P-A. Begreppet arbetsförmåga [The concept of work ability]. Linköpings universitet: IHS Rapport; 2006:1.

[23] Brülde B. Arbetsförmåga: Begrepp och etik [Work ability: Concept and ethics]. In: Vahlne Westerhäll L, editor. Arbets(o)förmåga - ur ett mångdisciplinärt perspektiv [Work (dis)ability - from a multidisciplinary perspective]. Stockholm: Santérus förlag; 2008. p. 195224.

[24] Ilmarinen J. Functional capacities and work ability as predictors of good 3rd age. In: Shiraki K, Sagawa S, Mohamed Yousef K, editors. Physical fitness and health promotion in active ageing. Leiden, The Netherlands: Backhuys Publishers; 2001. p. 61-80.

[25] Westerholm P, Bostedt G. Kan företagshälsovården lösa sjukskrivningskrisen? [Can the industrial health service solve the crisis in sick-listing?]. In: Hogstedt C, Bjurvald M, Marklund S, Palmer E, Theorell T, editors. Den höga sjukfrånvaron - sanning och konsekvens [The high absence due to illness - truth and consequences]. Stockholm: Statens folkhälsoinstitut; 2004. p. 303-344.

[26] Kielhofner G. A model of human occupation. 3rd ed. Baltimore: Lippincott, Williams \& Wilkins; 2002.

[27] Velozo CA. Work evaluations: critique of the state of the art of functional assessment. American Journal of Occupational Therapy, 1993; 47:203-209.

[28] Seelman, K. Trends in rehabilitation and disability: Transition from a medical model to an integrative model. DisabilityWorld (www.disabilityworld.org) (C) 2000-7 World Institute

Reprinted from Work: A Journal of Prevention, Assessment and Rehabilitation, vol x, issue $x$, Tengland, Per-Anders, A qualitative approach to assessing work ability, p. xx, Copyright (2012), http://dx.doi.org/10.3233/WOR-2012-1361 with 
on Disability; 2010 [Cited 2010 Sept 15] Available from http://www.disabilityworld.org/0103_04/access/rehabtrends1.shtml

[29] WHO. ICF, International Classification of Functioning, Disability and Health. Geneva:

World Health Organization; 2001.

[30] Tengland, P-A. Empowerment: A conceptual discussion. Health Care Analysis, 2008; 16(2):77-96.

[31] Sandqvist JL, Henriksson CM. Work functioning: A conceptual framework. Work, 2004; 23(2):147-157. 